\title{
Review Article \\ The Role of Neural Plasticity in Depression: From Hippocampus to Prefrontal Cortex
}

\author{
Wei Liu, ${ }^{1,2}$ Tongtong Ge, ${ }^{1}$ Yashu Leng, ${ }^{3}$ Zhenxiang Pan, ${ }^{2}$ \\ Jie Fan, ${ }^{1}$ Wei Yang, ${ }^{1}$ and Ranji Cui ${ }^{1}$ \\ ${ }^{1}$ Jilin Provincial Key Laboratory on Molecular and Chemical Genetic, The Second Hospital of Jilin University, \\ 218 Ziqiang Street, Changchun 130041, China \\ ${ }^{2}$ Anesthesiology Department, The Second Hospital of Jilin University, 218 Ziqiang Street, Changchun 130041, China \\ ${ }^{3}$ Anesthesiology Department, The Third Hospital of Jilin University, 126 Xiantai Street, Changchun 130033, China
}

Correspondence should be addressed to Wei Yang; wyang2002@jlu.edu.cn and Ranji Cui; cuiranji@jlu.edu.cn

Received 3 November 2016; Accepted 4 January 2017; Published 26 January 2017

Academic Editor: Aijun Li

Copyright (C) 2017 Wei Liu et al. This is an open access article distributed under the Creative Commons Attribution License, which permits unrestricted use, distribution, and reproduction in any medium, provided the original work is properly cited.

\begin{abstract}
Neural plasticity, a fundamental mechanism of neuronal adaptation, is disrupted in depression. The changes in neural plasticity induced by stress and other negative stimuli play a significant role in the onset and development of depression. Antidepressant treatments have also been found to exert their antidepressant effects through regulatory effects on neural plasticity. However, the detailed mechanisms of neural plasticity in depression still remain unclear. Therefore, in this review, we summarize the recent literature to elaborate the possible mechanistic role of neural plasticity in depression. Taken together, these findings may pave the way for future progress in neural plasticity studies.
\end{abstract}

\section{Introduction}

The establishment and realization of neural functions are based on generation, transformation, and storage of information in neural networks. The brain is developing and progressing at high speed in the six- to nineteen-year-old age group, and the unique plasticity of neural development is crucial to mature neural function. In a neural network, neurons are the fundamental functional units that integrate and transmit signals in response to intrinsic and extrinsic information [1]. Neuronal functions are dynamic processes that occur in response to environmental stimuli, emotions, injury, and so forth. This is the theoretical basis of neural plasticity, which is an umbrella term to describe structural and functional changes in the brain in response to various stimuli, including stress and depression. Depression is a prevalent, chronic, and recurrent disease. Depression, one of most devastating diseases, has a worldwide lifetime prevalence of $20 \%$. Moreover, to patients with depression, depression not only brings profound mental agony but also causes pathophysiological disorders and enhances susceptibility to some diseases, for instance, cardiac diseases and cerebrovascular illness [2]. Therefore, patients with depression suffer from higher mortality than the healthy population. Unfortunately, to date, no completely effective treatments for depressed patients have been developed. Currently available antidepressant treatments, whether medications, psychotherapies, or other methods, have limited efficacy in depression and can cause significant side effects [2]. Hence, it is profoundly significant to explore the pathophysiology of depression. Though a large number of studies on the correlation between depression and neural plasticity have revealed some of their mechanisms, the neurobiological mechanisms of depression are still not well known. Negative stimuli, such as stress, pain, and cognitive impairment, can result in both depression and changes in neural plasticity. The neuroplasticity hypothesis of major depressive disorder proposes the theory that dysfunction of neural plasticity is a basic pathomechanism of the disorder [3]. However, depression is not an inexorable outcome of dysfunction of neural plasticity. To our knowledge, there are no authoritative research results or expert consensus to confirm whether depression or changes 
in neural plasticity are the initial factor. Most of the studies suggest that depression and dysfunction of neural plasticity act on and influence each other. In this perspective, we review the recent literature to elaborate what is known about neural plasticity in depression to pave the way for ongoing and future studies.

\section{Hippocampal Plasticity in Depression}

The hippocampus is the most commonly studied brain region in depression research. From a structural point of view, the hippocampus is part of the limbic system and develops nerve fiber connectivity with emotion-related brain regions, for instance, the prefrontal cortex and amygdala. In addition, the hippocampus contains high levels of glucocorticoid receptors and glutamate and regulates the hypothalamus-pituitaryadrenal (HPA) axis, which makes it more susceptible to stress and depression. Changes in hippocampal plasticity can result from stress and other negative stimuli. Stress impacts hippocampal plasticity in many ways. Chronic and severe stress has been shown to impair hippocampus-dependent explicit memory in animal models of depression [4]. This effect can be explained by changes in hippocampal synaptic plasticity modeled by long-term potentiation (LTP) and longterm depression (LTD). Hippocampal synaptic plasticity is widely considered to play an important role in hippocampusdependent explicit memory formation [5]. Severe stress can impair LTP and enhance LTD in the hippocampi of rodent models $[6,7]$. Stress can also decrease neuronal dendrite branching and plasticity in the hippocampus [8]. In addition, stress can trigger activation of the hypothalamic-pituitaryadrenal axis, increase level of corticosteroids, and downregulate hippocampal neurogenesis [9]. Cognitive impairment can enhance long-term potentiation in the CA1 region and markedly elevate protein levels of the $\alpha$-amino-3-hydroxy5-methyl-4-isoxazolepropionic acid (AMPA) receptor subunit GluAl in the mouse hippocampus and then induce depression in mouse models [10]. In addition, neuropathic pain-induced depressive-like behavior may be associated with hippocampal neurogenesis and plasticity through tumor necrosis factor receptor 1 signaling [11]. Hippocampal plasticity in depression involves hippocampal volumetric changes, hippocampal neurogenesis, and apoptosis of hippocampal neurons.

2.1. Synaptic Plasticity in the Hippocampus. Synaptic plasticity is one of the most fundamental and important functions of the brain. The efficacy of transmission at a synapse depends on modulation of the connectivity between neurons and neuronal circuits during adaptation to the environment [12]. Stress has profound effects on synaptic plasticity in the hippocampus and presents different influences in different subfields of the hippocampus. Stress can impair LTP in CA3 while facilitating LTD and spike-timing-dependent LTD (tLTD) in CA1 [12]. In addition, depression can downregulate synaptic proteins and growth factors required for hippocampal LTP in animal models.

Electroacupuncture can alleviate depression-like behaviors and reverse the impairment induced by long-term potentiation in the CA1 synapses of the hippocampus in depressive rats [13]. Physical exercise may prevent changes in synaptic plasticity and increases in synaptic transmission in hippocampal CA1 pyramidal neurons caused by stress but cannot reverse the present glutamatergic synaptic alterations induced by depression [14]. Glucocorticoid receptor antagonists and monoaminergic antidepressants can protect against negative synaptic plasticity in CA1 induced by stress. TJZL184, a monoacylglycerol lipase inhibitor, exhibited antidepressant effects by enhancing adult neurogenesis and long-term synaptic plasticity in the dentate gyrus of the hippocampus [15]. Lycium barbarum was found to reduce depression-like behavior mediated by enhanced synaptic plasticity in the hippocampus of rats [16].

2.2. Hippocampal Volumetric Changes in Depression. It has been widely reported that there is a significant reduction in hippocampal volume in depression patients [17]. This situation was found in both adult and adolescent depressed patients, whether they were in their first or recurrent depressive episodes. A recent study reported that, in female patients with recurrent familial pure depressive disorder (rFPDD), volumetric reductions of the right hippocampal body and tail were significantly larger than those of the left, while the whole brain volume was approximately equal to that of healthy subjects [18]. Consistent with this, a significant increase in right hemispheric hippocampal gray matter volume has been found in elderly patients with severe depression treated with electroconvulsive therapy $[19,20]$. However, hippocampal volumetric reduction was also found in patients who had recovered from depression [17]. The volumetric changes may result from a neurodegenerative reaction to increased glucocorticoid levels in depression [20]. The changes in synaptic plasticity induced by depression are associated with structural and functional changes in the hippocampus. The volume reduction of the prefrontal cortex and hippocampus may also result from the disruption and atrophy of neurons and glia in depression [21, 22]. Nonetheless, the hippocampal volumetric changes are not associated with the severity of depression [18]. Evidence supports that larger hippocampal volumes indicate quicker recovery in depressed individuals [23]. This can be explained by hippocampal regulation in stress reactivity. Reduced hippocampal volumes may be a neural scar marker of depression and a vulnerability marker for future episodes [17]. The clinical application of hippocampal volumetric changes still needs large-sample research to confirm.

2.3. Hippocampal Neurogenesis. Brain neurogenesis lasts from birth to adulthood in many animals, including humans. Hippocampal neurogenesis occurs markedly in the dentate gyrus, with approximately 700 granule cells born daily, corresponding to an annual turnover of $1.75 \%$ of the neurons within the renewing fraction [24].

The rate of hippocampal neurogenesis decreases modestly with age. Compared with the millions of granule cells in the granular layer of the hippocampus, newborn neurons are few in number, but they can be sufficient to achieve functional 
significance [25]. Though the rates of neuronal regeneration are comparable in middle-aged humans and mice, the patterns of adult hippocampal neurogenesis are significantly different between them. In humans, approximately one-third of hippocampal neurons are subject to exchange. By contrast, the proportion is $10 \%$ in mice [26]. The relative decline rate of hippocampal neurogenesis during adulthood in humans is lower than that in mice. In addition, hippocampal neurogenesis in mice is additive, and newborn neurons can compensate for lost cells, while new neurons in humans cannot keep up with the losses [25]. Therefore, hippocampal neurogenesis in humans may have an additive function in the circuitry and enhance synaptic plasticity to achieve maximum impact.

The neurogenic hypothesis of depression emphasizes the theory that impaired adult hippocampal neurogenesis results in depression, and newborn neurons in the adult brain are critical to mood regulation and antidepressant efficacy [27, 28]. Impaired adult hippocampal neurogenesis and depression may be reciprocally causative [29]. High levels of glucocorticoids in depression also hinder adult hippocampal neurogenesis, but adrenalectomy can promote adult hippocampal neurogenesis.

The effects of antidepressant treatments on adult hippocampal neurogenesis have shown discrepancies in different species. In rodents, most antidepressant treatments that are used in humans, including electroconvulsive shock and medication, were subsequently shown to facilitate hippocampal neurogenesis [30-34]. However, the facilitation of fluoxetine treatment was sensitive to stress, corticosterone levels, and route of medication [29]. The effects of fluoxetine treatment on non-human primates are similar to those in rodents. In addition, electroconvulsive shock can also boost hippocampal neurogenesis in non-human primates [35]. There is a lack of research data to illustrate the effects of medication on non-human primates. In humans, total dentate granule cell number and dentate gyrus size in medicated patients with depression are larger than those in nonmedicated patients based on postmortem studies [36]. Selective serotonin reuptake inhibitors, lithium treatment, and electroconvulsive shock produce larger increases in hippocampus volume in treated depressed patients than in nontreated patients [37, 38]. In line with this observation, research evidence from the hippocampal subfields has revealed larger dentate gyri in medicated depressed patients [39]. These data are relevant to multiple forms of neural plasticity and suggest an increase in hippocampal neurogenesis. Nevertheless, there is no adequate evidence to establish that hippocampal neurogenesis is necessary for antidepressant efficacy, and its increase is sufficient for antidepressive therapy.

2.4. Hippocampal Apoptosis in Depression. Proliferation, differentiation, and apoptosis are continuous progressions in adult hippocampal neurons. Many studies have demonstrated that depression and stress can induce hippocampal apoptosis in rodents, non-human mammals, and humans, though hippocampal apoptosis can also be found in nondepressed rodents [40]. Similarly, hippocampal apoptosis may result in depression. Evidence showed an increase of apoptosis in dentate gyrus of maternal rats with repeated separation of their pups and impairment of memory capability with depressionlike behavioral changes [41]. In maternal-separation rat models, tadalafil, a phosphodiesterase type 5 inhibitor, exerts antidepressant effects by suppressing maternal-separationinduced apoptosis and increasing cell proliferation in the dentate gyrus [42]. Though some studies support the idea that hippocampal apoptosis is a causative factor in hippocampal volumetric changes, histopathological studies on depressed patients have yielded inconsistent results [43]. There are differences in the stimulative effects of chronic depression and acute depression on hippocampal apoptosis. In animal models and human studies, chronic depression showed longer lasting apoptosis-promoting effects in the hippocampus than acute depression [40]. The apoptosis-promoting effects induced by acute depression can fully subside in one day of recovery, while the adverse effects in chronic depression may need up to three weeks for recovery. However, it is uncertain in what stage depression and stress start to mediate apoptosis progression. In addition, their effects showed differences among subfields of the hippocampus. Compared with the apoptosis increase in the whole dentate gyrus caused by acute depression, the number of cells in the granular cell layer can increase even as the cell count in the whole dentate gyrus is declining [44]. This discrepancy may be due to the different sensitivities of granular cells to acute and chronic stress.

In addition to tadalafil (mentioned above), several types of drugs may have antidepressant effects owing to hippocampal apoptosis. For instance, venlafaxine, a serotonin/norepinephrine dual reuptake inhibitor, suppresses hippocampal apoptosis by upregulating brain-derived neurotrophic factor [45]. In addition, fluoxetine, a 5-hydroxytryptamine reuptake inhibitor, regulates hippocampal plasticity by alleviating the upregulation of synaptosomal polysialic neural cell adhesion molecule caused by depression and elicits an antiapoptotic response in the hippocampus [46].

\section{The Prefrontal Cortex in Depression}

The prefrontal cortex (PFC), as a significant nerve center of thinking and behavior regulation in the brain, is also associated with depression [47]. In view of anatomical connectivity and functional specialization, the prefrontal cortex is divided into two subregions: ventromedial prefrontal cortex (vmPFC) and dorsolateral sectors (dlPFC) [48]. VmPFC involves the regulation of affection, including the generation of negative emotion, and dlPFC mediates cognitive functions, such as intention formation, goal-directed action, and attentional control [49]. The two sectors have both been shown to have significant roles in depression. However, their effects present discrepancies, according to reports in the literature. Functional imaging studies have shown opposite changes of activity in the two sectors: during the progression of depression, hyperactivity appeared in the vmPFC, while hypoactivity appeared in dlPFC; in the recovery phase in response to psychotherapy or medication for depression, hypoactivity was found in the vmPFC, while hyperactivity was found in dlPFC $[48,50-53]$. Furthermore, in lesion models, dlPFC loss can aggravate depression, whereas vmPFC loss can exhibit an alleviative effect on depression [54, 55]. Dysfunction caused 
by dIPFC damage in stroke is considered a predisposing factor to poststroke depression [56]. In addition, a decrease of cortical thickness in the right vmPFC, which occurs in the early stages of neurodevelopment, results in depression in preschoolers [57]. Volume reduction of the prefrontal cortex may result from the disruption and atrophy of neurons and glia in depression, as observed in the hippocampus [21, 22]. Energy and glutathione metabolic pathways in the prefrontal cortex were shown to be significant biological pathways in depressive rats [58]. Many studies have indicated that changes in glutamate metabolism were associated with depression [59-67]. In a stress-induced depressive mouse model, the prefrontal cortex in depression showed a significant reduction of glutamate in the GABAergic pathway, which may contribute to depression [62]. Activation of metabotropic glutamate receptor 3, which plays a significant role in regulating the function and cognition of the prefrontal cortex, can result in long-term depression in the medial prefrontal cortex of rats in vitro [68]. The GRIN2A gene, which encodes the glutamatergic N-methyl-D-aspartate (NMDA) receptor subunit epsilon-1 in the prefrontal cortex, is probably disturbed in the regulation of synaptic plasticity in depression [69].

In addition, a novel miRNA (miR-101b) was found to be downregulated in depression and could decrease mRNA and protein levels of glutamate transporter SLC1A1 in the prefrontal cortex [59]. In addition, in the medial prefrontal cortices of chronic unpredictable mild stress-induced depressive mice, there was a downregulation of mRNAs encoding proteins for the GABAergic synapses, dopaminergic synapses, synaptic vesicle cycle, and neuronal growth and an upregulation of miRNAs of regulating these mRNAs [70]. In a chronic corticosterone-mediated depressive rat model, the majority of the related miRNAs and associated gene networks showed glucocorticoid receptor element binding sites; this is a potential mechanism whereby corticosterone may mediate depression [71].

There is also a decrease in prefrontal hemodynamic responses in depression and a significant and positive correlation between prefrontal hemodynamic responses and the role of the emotional domain $[72,73]$. In addition, the lack of activation of oxygenated hemoglobin in the prefrontal cortex indicates that it may be a mechanism of depression [74]. Observing changes in hemoglobin concentration in the prefrontal cortex detected by near-infrared spectroscopy may be a convenient approach to evaluate and predict antidepressant improvement in late-onset depression [58]. Furthermore, increases in mean oxygenated hemoglobin may be positively correlated with the severity of depression [75].

Repetitive transcranial magnetic stimulation of the dorsomedial prefrontal cortex (dmPFC) and dlPFC exhibits effectiveness and safety in treatment-resistant depression [76-80]. In electroconvulsive therapy for depression, an early decrease of intralimbic functional connectivity and a later increase of limbic-prefrontal functional connectivity were found [81]. Epidural prefrontal cortical stimulation over the PFC has also been shown to be a promising novel therapeutic method for treatment-resistant depression [82]. Positive emotional learning can facilitate N-methyl-Daspartate (NMDA) receptor-dependent synaptic plasticity in the medial prefrontal cortex and then exert positive effects on promoting rehabilitation in depressive rats [83]. Some studies have reported that NMDA receptor antagonists, such as ketamine and lanicemine, can increase mammalian target of rapamycin complex 1 (mTORC1) signaling by activating threonine kinase (AKT) and extracellular signal-regulated kinase (ERK) signaling pathways and increase synaptic number and function in the prefrontal cortex $[2,84,85]$. A recent study on protein level changes in the prefrontal cortex suggested that treatment with the tricyclic antidepressant clomipramine in neonates was a reliable model to study the effects of antidepressants on the early phase of brain development [86]. Hence, the effects of antidepressant treatment on early brain development may induce constant pathological changes in the prefrontal cortex. YY-23, a new extractive compound, and fluoxetine can reverse the inhibitory effects of chronic mild stress on spontaneous burst firing of medial prefrontal cortex pyramidal neurons in depression [87]. Mecamylamine, a nicotinic antagonist, is a novel antidepressant that exerts antidepressant actions by increasing PFC levels of BDNF and monoamines [88]. Interestingly, in a depressive rat model, nutritional supplements, such as n-3 polyunsaturated fatty acids (PUFA), may prevent the development of depression by impeding HPA axis hyperactivity [89]. This study suggests that dystrophy may be another mechanism of depression.

\section{Amygdalar Changes in Depression}

The amygdala plays a significant role in affective modulation and memory encoding [90]. The amygdala is also a critical site of neuronal plasticity for fear conditioning [91]. Morphological and functional changes of the amygdala associated with depression have been verified in many studies [92, 93]. In contrast, with the hippocampus and prefrontal cortex, stress and depression enhance synaptic plasticity in the amygdala and the ventral emotional network [3]. Stress was found to induce dendrite retraction in the PFC and hippocampus, while it induced dendritic arborization of pyramidal and spiny neurons in the basolateral amygdala [12]. Expression of brain-derived neurotrophic factor (BDNF), which is known to play a central role in synaptic plasticity induced by stress, increased in the basolateral amygdala but decreased in the hippocampal CA3 in rats $[9,94]$. Depression disrupted glutamate signaling at the NMDA receptor in the amygdala in humans [95]. Neonatal glucocorticoid treatment enhanced LTP response and the phosphorylation level of MAPK in the lateral nucleus of the amygdala and promoted depression-like behavior in adult rats [91].

Amygdala kindling, as a classic model of temporal lobe epilepsy with convulsion, can cause depression-like behaviors in both immature rats and adult rats [96]. Amygdalar functional connectivity differs in late-life depression phenotypes, and this discrepancy may be a criterion to distinguish phenotypes of late-life depression and evaluate the severity [97].

In addition, the volume of the amygdala varied with the severity of the depression [98]. Interestingly, a recent study showed that larger gray matter volume in the bilateral amygdala was found in first-degree relatives of depressed 
patients [99]. Furthermore, amygdala perturbations caused by negative stimuli, which elicit greater amygdala activation, might be an early and subtle risk marker for depression [100]. Recent evidence suggests that postpartum depression can increase amygdalar response to infant stimuli and decrease bilateral amygdala-right insular cortex connectivity [101]. The latter may have a stimulative effect on depression and anxiety. However, abnormal functional connectivity in depression is discrepant in the left amygdala [102]. In the left amygdala, the functional connectivity decreased in the amygdala positive network, while it increased in the amygdala negative network. In a clinical study of early-childhood-onset depression, functional connectivity was reduced in the bilateral amygdala [103]. Abnormal amygdala functional connectivity is also found in late-onset depressed patients [104]. Hence, a distributed neuronal network including cortical and limbic regions rather than a discrete brain region contributes to depression. The amygdala-associated frontolimbic circuits, amygdala-dorsal lateral prefrontal cortex, and amygdalaventromedial prefrontal cortex, which integrate affective processes, may have characteristic dysfunctions in adolescent depression [104]. These circuits may change exponentially in association with depression severity and potentially be considered as a biomarker to analyze the effect of treatment on depression. Interestingly, some of the amygdalar changes in depression differ by gender. A recent study indicated that women but not men possess an IL18 haplotype that increases threat-related left centromedial amygdala reactivity and boosts susceptibility to stress-related depression by promoting proinflammatory responses [105]. Depression-associated single-nucleotide polymorphisms can regulate the expression of the bicaudal C homolog 1 (BICC1) gene and decrease its promoter activity on the PKA signaling pathway in amygdalar neurons [106]. These changes may cause mood disorders. In addition, prenatal maternal depression can influence the functional connectivity of the amygdala in early postnatal life, particularly in 6-month-old infants [107]. Prenatal maternal depression can also incur the risk of aggression in offspring [108]. In contrast, many studies have suggested that amygdala hyperactivity may improve symptoms of depression [109].

Some antidepressant treatments have been shown to play a role in amygdala regulation. Transcutaneous vagus nerve stimulation is a noninvasive peripheral neuromodulation therapy administered at the ear for depressed patients and has been shown to be effective for depression treatment [110]. It can promote amygdala-lateral prefrontal network resting state functional connectivity in the right amygdala of depressed patients [111]. Real-time fMRI neurofeedback training is another novel noninvasive treatment for depression [112]. It can enhance blood-oxygenation-leveldependent activity in the amygdala and benefit depressed patients. In addition, the effects of electroconvulsive therapy in patients with depression may also be associated with neuroplasticity changes in the amygdala, and this phenomenon may be due to neurotrophic processes, including neurogenesis [112]. Medication associated with the amygdala in depressed patients includes quetiapine, citalopram, and ketamine [113-115]. In depressive rat models, the amygdala has shown a significant role in fluoxetine-stimulated cell survival and a potential to modulate antidepressant action in hippocampal neurogenesis [116].

\section{Neural Plasticity in Other Brain Regions in Depression}

The ventral striatum participates in the mechanisms of natural reward, and its dysregulation contributes to symptoms of anhedonia in depression [4]. Chronic stress can cause longterm adaptations in the ventral tegmental area-accumbens pathway that may contribute to its dysregulation in major depression [4]. $\alpha_{1}$-Adrenoceptor dependent downregulation of the membrane GluR1 subunit in the mouse ventral tegmental area mediated the depressive-like behavior induced by lipopolysaccharide [117]. In rats with postpartum depression, gestational stress could decrease dendritic length, branching, and spine density on medium spiny neurons in the nucleus accumbens shell and promote depressive-like behavior in the early/mid-postpartum phase [118].

Hypothalamic synaptic plasticity in depression can be caused by increased mRNA expression of synaptotagmin I and synapsin I, and the latter may contribute to depressionlike behaviors and HPA axis hyperactivity [119]. In addition, the extracellular matrix may be involved in synaptic stabilization and transmission and may modulate synaptic plasticity in the central nervous system [120]. In recent studies, modeling of bidirectional modulations in synaptic plasticity, designed to reveal the mechanism of long-term potentiation and long-term depression, suggested that $\mathrm{Ca}^{2+} /$ calmodulin $(\mathrm{CaM})$ pool size played a critical role in coordinating LTP/LTD expression [121].

\section{Summary and Conclusion}

Overall, neural plasticity is a vital feature of the brain in response to intrinsic and extrinsic stimuli, including stress and depression. Mounting clinical and basic research studies have illuminated the correlations between neural plasticity and depression. As the summaries in Tables 1 and 2 , the effects of depression on neural plasticity are complex pathophysiological processes, involving multiple encephalic regions, such as the hippocampus, prefrontal cortex, and amygdala as well as complicated interactions of many signal pathways, such as NMDA, glutamate, and glucocorticoid. On the other hand, the changes in neural plasticity induced by stress and other negative stimuli can contribute to the onset and development of depression. The majority of antidepressant treatments, including psychotherapies, physiotherapies, and medications, exert antidepressant effects associated with neural plasticity. Unfortunately, to date, no ideal and completely effective treatment has been found for depressed patients. Though we have done extensive work in this review, the detailed mechanisms of neural plasticity in depression still remain unclear. Targeting neural plasticity in depression may lead to novel breakthroughs.

\section{Competing Interests}

The authors confirm that this article content has no conflict of interests. 
TABLE 1: Changes of neural plasticity induced by depression in various brain regions.

\begin{tabular}{|c|c|c|}
\hline Brain region & Changes of neural plasticity & Mechanisms \\
\hline \multirow{10}{*}{ Hippocampus } & \multirow{3}{*}{ Synaptic plasticity } & (1) Impairment of LTP in CA3 \\
\hline & & (2) Facilitation of LTD and tLTD in CA1 \\
\hline & & (3) Downregulation of synaptic proteins and growth factors \\
\hline & \multirow[b]{2}{*}{ Volumetric changes } & (1) Disruption and atrophy of neurons and glia \\
\hline & & $\begin{array}{l}\text { (2) Neurodegenerative reaction to high levels of } \\
\text { glucocorticoid }\end{array}$ \\
\hline & \multirow{3}{*}{ Neurogenesis } & $\begin{array}{l}\text { (1) Hindered by high levels of glucocorticoids and enhanced } \\
\text { by adrenalectomy }\end{array}$ \\
\hline & & (2) Additive effects in mice, while reduced in humans \\
\hline & & (3) Additive function in the circuitry \\
\hline & \multirow[b]{2}{*}{ Apoptosis } & (1) Depression promotes apoptosis in the hippocampus \\
\hline & & $\begin{array}{l}\text { (2) The effects caused by chronic depression last longer than } \\
\text { those of acute depression }\end{array}$ \\
\hline \multirow{11}{*}{ Prefrontal cortex } & \multirow{3}{*}{ Synaptic plasticity } & (1) Disturb expression of NMDA receptor gene \\
\hline & & $\begin{array}{l}\text { (2) Downregulation of proteins for the GABAergic synapses, } \\
\text { dopaminergic synapses, synaptic vesicle cycle }\end{array}$ \\
\hline & & $\begin{array}{l}\text { (3) Downregulation of mRNA and protein levels of glutamate } \\
\text { transporter SLC1A1 }\end{array}$ \\
\hline & \multirow{2}{*}{$\begin{array}{l}\text { Activity in vmPFC and } \\
\text { dlPFC }\end{array}$} & $\begin{array}{l}\text { (1) Hyperactivity in vmPFC and hypoactivity in dlPFC } \\
\text { during progression of depression; hyperactivity in dlPFC and } \\
\text { hypoactivity in vmPFC during recovery phase }\end{array}$ \\
\hline & & $\begin{array}{l}\text { (2) Decrease of cortical thickness of right vmPFC through } \\
\text { disruption and atrophy of neurons and glia }\end{array}$ \\
\hline & \multirow{4}{*}{ Energetic metabolism } & (1) Reduction of glutamate in the GABAergic pathway \\
\hline & & (2) Activation of metabotropic glutamate receptor 3 \\
\hline & & (3) Disturbed expression of NMDA receptor gene \\
\hline & & $\begin{array}{l}\text { (4) Downregulation mRNA and protein levels of glutamate } \\
\text { transporter SLC1A1 }\end{array}$ \\
\hline & & (1) Lack of activation of oxygenated hemoglobin \\
\hline & Hemodynamic responses & $\begin{array}{l}\text { (2) Changes in hemoglobin concentration may be positively } \\
\text { correlated with severity of depression }\end{array}$ \\
\hline \multirow{7}{*}{ Amygdala } & \multirow[b]{2}{*}{ Synaptic plasticity } & (1) Increased expression of BDNF \\
\hline & & $\begin{array}{l}\text { (2) Disrupted glutamate signaling at the NMDA receptor } \\
\text { (3) Neonatal glucocorticoid treatment enhances LTP } \\
\text { response }\end{array}$ \\
\hline & Volumetric changes & (1) Larger gray matter volume in the bilateral amygdala \\
\hline & \multirow{4}{*}{ Functional connectivity } & $\begin{array}{l}\text { (1) Decreased bilateral amygdala-right insular cortex } \\
\text { connectivity }\end{array}$ \\
\hline & & $\begin{array}{l}\text { (2) In the left amygdala, the functional connectivity } \\
\text { decreased in positive network and increased in negative } \\
\text { network }\end{array}$ \\
\hline & & $\begin{array}{l}\text { (3) Amygdala-associated brain circuits may change with } \\
\text { depression severity }\end{array}$ \\
\hline & & $\begin{array}{l}\text { (4) Prenatal maternal depression increases functional } \\
\text { connectivity in infants }\end{array}$ \\
\hline \multirow{3}{*}{ Ventral striatum } & & $\begin{array}{l}\text { (1) Caused long-term adaptations in the ventral tegmental } \\
\text { area-accumbens pathway }\end{array}$ \\
\hline & & $\begin{array}{l}\text { (2) } \alpha_{1} \text {-Adrenoceptor dependent downregulation of the } \\
\text { membrane GluR1 subunit }\end{array}$ \\
\hline & & $\begin{array}{l}\text { (3) Decreased dendritic length, branching, spine density on } \\
\text { medium spiny neurons in the nucleus accumbens shell }\end{array}$ \\
\hline Hypothalamus & Synaptic plasticity & $\begin{array}{l}\text { (1) Increased mRNA expression of } \\
\text { synaptotagmin I and synapsin I }\end{array}$ \\
\hline
\end{tabular}


TABLE 2: Neural plasticity in the treatment of depression.

\begin{tabular}{lc}
\hline Therapy & Model \\
\hline Electroacupuncture & Rats \\
\hline
\end{tabular}

Mechanism and influence of neural plasticity Reverses the impairment induced by long-term potentiation in CA1 synapses of hippocampus Facilitates hippocampal neurogenesis, an early decrease of intralimbic functional connectivity and a

Electroconvulsive shock Rats and humans later increase of limbic-prefrontal functional connectivity, and makes neuroplasticity changes in the amygdala due to neurotrophic processes including neurogenesis

\begin{tabular}{|c|c|c|}
\hline $\begin{array}{l}\text { Transcutaneous vagus } \\
\text { nerve stimulation }\end{array}$ & Humans & $\begin{array}{l}\text { Promotes amygdala-lateral prefrontal network } \\
\text { resting state functional connectivity in right amygdala }\end{array}$ \\
\hline $\begin{array}{l}\text { Real-time fMRI } \\
\text { neurofeedback training }\end{array}$ & Humans & $\begin{array}{l}\text { Enhances blood-oxygenation-level-dependent activity } \\
\text { in amygdala }\end{array}$ \\
\hline Positive emotional learning & Rats & $\begin{array}{l}\text { Facilitates N-methyl-D-aspartate (NMDA) } \\
\text { receptor-dependent synaptic plasticity learning }\end{array}$ \\
\hline Physical exercise & Rats & $\begin{array}{l}\text { Prevents changes in synaptic plasticity and } \\
\text { increases in synaptic transmission in } \\
\text { hippocampal CA1 pyramidal neurons caused } \\
\text { by stress }\end{array}$ \\
\hline $\begin{array}{l}\text { Nutritional substance } \\
\text { supplementation }\end{array}$ & Rats & $\begin{array}{l}\text { Prevents the development of depression through } \\
\text { impeding HPA axis hyperactivity }\end{array}$ \\
\hline $\begin{array}{l}\text { Glucocorticoid receptor } \\
\text { antagonists }\end{array}$ & Rats & $\begin{array}{l}\text { Protects against negative synaptic plasticity in CA1 } \\
\text { induced by stress }\end{array}$ \\
\hline $\begin{array}{l}\text { Monoaminergic } \\
\text { antidepressants }\end{array}$ & Rats & $\begin{array}{l}\text { Protects against negative synaptic plasticity in CA1 } \\
\text { induced by stress }\end{array}$ \\
\hline $\begin{array}{l}\text { TJZL184 (a } \\
\text { monoacylglycerol lipase } \\
\text { inhibitor) }\end{array}$ & Rats & $\begin{array}{l}\text { Enhances adult neurogenesis and long-term } \\
\text { synaptic plasticity in the DG of the hippocampus }\end{array}$ \\
\hline Lycium barbarum & Rats & Enhances synaptic plasticity in the hippocampus \\
\hline $\begin{array}{l}\text { Lithium (selective } \\
\text { serotonin reuptake } \\
\text { inhibitor) }\end{array}$ & Rats and humans & Facilitates hippocampal neurogenesis \\
\hline $\begin{array}{l}\text { Fluoxetine (selective } \\
\text { serotonin reuptake } \\
\text { inhibitor) }\end{array}$ & Rats & $\begin{array}{l}\text { Amygdala neuroplasticity, alleviates upregulation of } \\
\text { synaptosomal polysialic neural cell adhesion } \\
\text { molecule and reverses the inhibitory effects of } \\
\text { chronic mild stress on spontaneous burst firing of } \\
\text { medial prefrontal cortex pyramidal neurons }\end{array}$ \\
\hline $\begin{array}{l}\text { Tadalafil } \\
\text { (phosphodiesterase } \\
\text { inhibitor) }\end{array}$ & Rats & $\begin{array}{l}\text { Suppresses maternal separation-induced apoptosis } \\
\text { and increases cell proliferation in the dentate gyrus }\end{array}$ \\
\hline $\begin{array}{l}\text { Venlafaxine } \\
\text { (serotonin/norepinephrine } \\
\text { dual reuptake inhibitor) }\end{array}$ & Rats & $\begin{array}{l}\text { Suppresses hippocampal apoptosis by } \\
\text { upregulating brain-derived neurotrophic factor }\end{array}$ \\
\hline $\begin{array}{l}\text { Ketamine and lanicemine } \\
\text { (NMDA receptor } \\
\text { antagonists) }\end{array}$ & Rats & $\begin{array}{l}\text { Increases mammalian target of rapamycin complex } 1 \\
\text { (mTORC1) signaling by activating threonine kinase } \\
\text { (AKT) and extracellular signal-regulated kinase (ERK) } \\
\text { signaling pathways and increases synaptic number and } \\
\text { function in the prefrontal cortex }\end{array}$ \\
\hline $\begin{array}{l}\text { Mecamylamine (nicotinic } \\
\text { antagonist) }\end{array}$ & Rats & Increases PFC levels of BDNF and monoamines \\
\hline
\end{tabular}

\section{Acknowledgments}

This work was supported by grants from the Natural Science Foundation of China (NSFC) (nos. 31471120, 31540076, and 31171123) and the Program for New Century Excellent Talents in University (NCET-13-0715).

\section{References}

[1] S. R. Wainwright and L. A. M. Galea, "The neural plasticity theory of depression: assessing the roles of adult neurogenesis and psa-ncam within the hippocampus," Neural Plasticity, vol. 2013, Article ID 805497, 14 pages, 2013. 
[2] R. S. Duman, G. K. Aghajanian, G. Sanacora, and J. H. Krystal, "Synaptic plasticity and depression: new insights from stress and rapid-acting antidepressants," Nature Medicine, vol. 22, no. 3, pp. 238-249, 2016.

[3] M. Kuhn, N. Höger, B. Feige, J. Blechert, C. Normann, and C. Nissen, "Fear extinction as a model for synaptic plasticity in major depressive disorder," PLoS ONE, vol. 9, no. 12, Article ID el15280, 2014.

[4] C. Pittenger and R. S. Duman, "Stress, depression, and neuroplasticity: a convergence of mechanisms," Neuropsychopharmacology, vol. 33, no. 1, pp. 88-109, 2008.

[5] R. C. Malenka and M. F. Bear, "LTP and LTD: an embarrassment of riches," Neuron, vol. 44, no. 1, pp. 5-21, 2004.

[6] J. J. Kim and D. M. Diamond, "The stressed hippocampus, synaptic plasticity and lost memories," Nature Reviews Neuroscience, vol. 3, no. 6, pp. 453-462, 2002.

[7] L. Xu, R. Anwyl, and M. J. Rowan, "Behavioural stress facilitates the induction of long-term depression in the hippocampus," Nature, vol. 387, no. 6632, pp. 497-500, 1997.

[8] H. Son, M. Banasr, M. Choi et al., "Neuritin produces antidepressant actions and blocks the neuronal and behavioral deficits caused by chronic stress," Proceedings of the National Academy of Sciences of the United States of America, vol. 109, no. 28, pp. 11378-11383, 2012.

[9] G. Masi and P. Brovedani, “The hippocampus, neurotrophic factors and depression: possible implications for the pharmacotherapy of depression," CNS Drugs, vol. 25, no. 11, pp. 913-931, 2011.

[10] M. Gross, A. Sheinin, E. Nesher et al., "Early onset of cognitive impairment is associated with altered synaptic plasticity and enhanced hippocampal GluA1 expression in a mouse model of depression," Neurobiology of Aging, vol. 36, no. 5, pp. 1938-1952, 2015.

[11] A. Dellarole, P. Morton, R. Brambilla et al., "Neuropathic paininduced depressive-like behavior and hippocampal neurogenesis and plasticity are dependent on TNFR1 signaling," Brain, Behavior, and Immunity, vol. 41, no. 1, pp. 65-81, 2014.

[12] W. N. Marsden, "Synaptic plasticity in depression: molecular, cellular and functional correlates," Progress in NeuroPsychopharmacology and Biological Psychiatry, vol. 43, pp. 168184, 2013.

[13] Y. She, J. Xu, Y. Duan et al., "Possible antidepressant effects and mechanism of electroacupuncture in behaviors and hippocampal synaptic plasticity in a depression rat model," Brain Research, vol. 1629, pp. 291-297, 2015.

[14] M. Gómez-Galán, T. Femenía, E. Åberg et al., "Running opposes the effects of social isolation on synaptic plasticity and transmission in a rat model of depression," PLOS ONE, vol. 11, no. 10, Article ID e0165071, 2016.

[15] Z. Zhang, W. Wang, P. Zhong et al., "Blockade of 2-arachidonoylglycerol hydrolysis produces antidepressant-like effects and enhances adult hippocampal neurogenesis and synaptic plasticity," Hippocampus, vol. 25, no. 1, pp. 16-26, 2015.

[16] E. Zhang, S. Y. Yau, B. W. M. Lau et al., "Synaptic plasticity, but not hippocampal neurogenesis, mediated the counteractive effect of wolfberry on depression in rats," Cell Transplantation, vol. 21, no. 12, pp. 2635-2649, 2012.

[17] S. W. Y. Chan, C. J. Harmer, R. Norbury, U. O’Sullivan, G. M. Goodwin, and M. J. Portella, "Hippocampal volume in vulnerability and resilience to depression," Journal of Affective Disorders, vol. 189, pp. 199-202, 2016.
[18] F. Nifosì, T. Toffanin, H. Follador et al., "Reduced right posterior hippocampal volume in women with recurrent familial pure depressive disorder," Psychiatry Research-Neuroimaging, vol. 184, no. 1, pp. 23-28, 2010.

[19] F. Bouckaert, F.-L. De Winter, L. Emsell et al., "Grey matter volume increase following electroconvulsive therapy in patients with late life depression: A Longitudinal MRI Study," Journal of Psychiatry and Neuroscience, vol. 41, no. 2, pp. 105-114, 2016.

[20] Y. I. Sheline, "Depression and the hippocampus: cause or effect?” Biological Psychiatry, vol. 70, no. 4, pp. 308-309, 2011.

[21] R. S. Duman and G. K. Aghajanian, "Synaptic dysfunction in depression: potential therapeutic targets," Science, vol. 338, no. 6103, pp. 68-72, 2012.

[22] B. S. McEwen, L. Eiland, R. G. Hunter, and M. M. Miller, "Stress and anxiety: structural plasticity and epigenetic regulation as a consequence of stress," Neuropharmacology, vol. 62, no. 1, pp. 3-12, 2012.

[23] G. M. MacQueen, K. Yucel, V. H. Taylor, K. Macdonald, and R. Joffe, "Posterior hippocampal volumes are associated with remission rates in patients with major depressive disorder," Biological Psychiatry, vol. 64, no. 10, pp. 880-883, 2008.

[24] E. Fuchs and E. Gould, "In vivo neurogenesis in the adult brain: regulation and functional implications," European Journal of Neuroscience, vol. 12, no. 7, pp. 2211-2214, 2000.

[25] K. L. Spalding, O. Bergmann, K. Alkass et al., "Dynamics of hippocampal neurogenesis in adult humans," Cell, vol. 153, no. 6, pp. 1219-1227, 2013.

[26] I. Imayoshi, M. Sakamoto, T. Ohtsuka et al., "Roles of continuous neurogenesis in the structural and functional integrity of the adult forebrain," Nature Neuroscience, vol. 11, no. 10, pp. 11531161, 2008.

[27] B. L. Jacobs, H. Van Praag, and F. H. Gage, "Adult brain neurogenesis and psychiatry: a novel theory of depression," Molecular Psychiatry, vol. 5, no. 3, pp. 262-269, 2000.

[28] D. Petrik, D. C. Lagace, and A. J. Eisch, "The neurogenesis hypothesis of affective and anxiety disorders: are we mistaking the scaffolding for the building?" Neuropharmacology, vol. 62, no. 1, pp. 21-34, 2012.

[29] B. R. Miller and R. Hen, "The current state of the neurogenic theory of depression and anxiety," Current Opinion in Neurobiology, vol. 30, pp. 51-58, 2015.

[30] T. M. Madsen, A. Treschow, J. Bengzon, T. G. Bolwig, O. Lindvall, and A. Tingström, "Increased neurogenesis in a model of electroconvulsive therapy," Biological Psychiatry, vol. 47, no. 12, pp. 1043-1049, 2000.

[31] B. W. Scott, J. M. Wojtowicz, and W. M. Burnham, "Neurogenesis in the dentate gyrus of the rat following electroconvulsive shock seizures," Experimental Neurology, vol. 165, no. 2, pp. 231236, 2000.

[32] G. Chen, G. Rajkowska, F. Du, N. Seraji-Bozorgzad, and H. K. Manji, "Enhancement of hippocampal neurogenesis by lithium," Journal of Neurochemistry, vol. 75, no. 4, pp. 1729-1734, 2000.

[33] J. Benninghoff, H. Grunze, C. Schindler et al., "Ziprasidonenot haloperidol-induces more de-novo neurogenesis of adult neural stem cells derived from murine hippocampus," Pharmacopsychiatry, vol. 46, no. 1, pp. 10-15, 2013.

[34] G. Keilhoff, H.-G. Bernstein, A. Becker, G. Grecksch, and G. Wolf, "Increased neurogenesis in a rat ketamine model of schizophrenia," Biological Psychiatry, vol. 56, no. 5, pp. 317-322, 2004. 
[35] T. D. Perera, J. D. Coplan, S. H. Lisanby et al., "Antidepressantinduced neurogenesis in the hippocampus of adult nonhuman primates," Journal of Neuroscience, vol. 27, no. 18, pp. 4894-4901, 2007.

[36] M. Boldrini, T. H. Butt, A. N. Santiago et al., "Benzodiazepines and the potential trophic effect of antidepressants on dentate gyrus cells in mood disorders," International Journal of Neuropsychopharmacology, vol. 17, no. 12, pp. 1923-1933, 2014.

[37] B. Hallahan, J. Newell, J. C. Soares et al., "Structural magnetic resonance imaging in bipolar disorder: an international collaborative mega-analysis of individual adult patient data," Biological Psychiatry, vol. 69, no. 4, pp. 326-335, 2011.

[38] I. Tendolkar, M. van Beek, I. van Oostrom et al., "Electroconvulsive therapy increases hippocampal and amygdala volume in therapy refractory depression: A Longitudinal Pilot Study," Psychiatry Research-Neuroimaging, vol. 214, no. 3, pp. 197-203, 2013.

[39] Y. Huang, N. J. Coupland, R. M. Lebel et al., "Structural changes in hippocampal subfields in major depressive disorder: a highfield magnetic resonance imaging study," Biological Psychiatry, vol. 74, no. 1, pp. 62-68, 2013.

[40] P. J. Lucassen, V. M. Heine, M. B. Muller et al., "Stress, depression and hippocampal apoptosis," CNS and Neurological Disorders-Drug Targets, vol. 5, no. 5, pp. 531-546, 2006.

[41] Y.-H. Sung, M.-S. Shin, S. Cho et al., "Depression-like state in maternal rats induced by repeated separation of pups is accompanied by a decrease of cell proliferation and an increase of apoptosis in the hippocampus," Neuroscience Letters, vol. 470, no. 1, pp. 86-90, 2010.

[42] S.-B. Baek, G. Bahn, S.-J. Moon et al., "The phosphodiesterase type-5 inhibitor, tadalafil, improves depressive symptoms, ameliorates memory impairment, as well as suppresses apoptosis and enhances cell proliferation in the hippocampus of maternal-separated rat pups," Neuroscience Letters, vol. 488, no. 1, pp. 26-30, 2011.

[43] B. Czéh and P. J. Lucassen, "What causes the hippocampal volume decrease in depression? Are neurogenesis, glial changes and apoptosis implicated?" European Archives of Psychiatry and Clinical Neuroscience, vol. 257, no. 5, pp. 250-260, 2007.

[44] V. M. Heine, S. Maslam, J. Zareno, M. Joëls, and P. J. Lucassen, "Suppressed proliferation and apoptotic changes in the rat dentate gyrus after acute and chronic stress are reversible," European Journal of Neuroscience, vol. 19, no. 1, pp. 131-144, 2004.

[45] X. Huang, Y.-S. Mao, C. Li, H. Wang, and J.-L. Ji, "Venlafaxine inhibits apoptosis of hippocampal neurons by up-regulating brain-derived neurotrophic factor in a rat depression model," Pharmazie, vol. 69, no. 12, pp. 909-916, 2014.

[46] A. Djordjevic, J. Djordjevic, I. Elaković, M. Adzic, G. Matić, and M. B. Radojcic, "Fluoxetine affects hippocampal plasticity, apoptosis and depressive-like behavior of chronically isolated rats," Progress in Neuro-Psychopharmacology and Biological Psychiatry, vol. 36, no. 1, pp. 92-100, 2012.

[47] M. T. Treadway, M. L. Waskom, D. G. Dillon et al., "Illness progression, recent stress, and morphometry of hippocampal subfields and medial prefrontal cortex in major depression," Biological Psychiatry, vol. 77, no. 3, pp. 285-294, 2015.

[48] M. Koenigs and J. Grafman, "The functional neuroanatomy of depression: distinct roles for ventromedial and dorsolateral prefrontal cortex," Behavioural Brain Research, vol. 201, no. 2, pp. 239-243, 2009.
[49] E. K. Miller and J. D. Cohen, "An integrative theory of prefrontal cortex function," Annual Review of Neuroscience, vol. 24, pp. 167-202, 2001.

[50] H. S. Mayberg, A. M. Lozano, V. Voon et al., "Deep brain stimulation for treatment-resistant depression," Neuron, vol. 45, no. 5, pp. 651-660, 2005.

[51] M. D. Greicius, B. H. Flores, V. Menon et al., "Resting-state functional connectivity in major depression: abnormally increased contributions from subgenual cingulate cortex and thalamus," Biological Psychiatry, vol. 62, no. 5, pp. 429-437, 2007.

[52] H. S. Mayberg, S. K. Brannan, J. L. Tekell et al., "Regional metabolic effects of fluoxetine in major depression: serial changes and relationship to clinical response," Biological Psychiatry, vol. 48, no. 8, pp. 830-843, 2000.

[53] H. S. Mayberg, M. Liotti, S. K. Brannan et al., "Reciprocal limbic-cortical function and negative mood: converging PET findings in depression and normal sadness," American Journal of Psychiatry, vol. 156, no. 5, pp. 675-682, 1999.

[54] J. M. Ellenbogen, M. O. Hurford, D. S. Liebeskind, G. B. Neimark, and D. Weiss, "Ventromedial frontal lobe trauma," Neurology, vol. 64, no. 4, p. 757, 2005.

[55] P. S. Sachdev and J. Sachdev, "Long-term outcome of neurosurgery for the treatment of resistant depression," Journal of Neuropsychiatry and Clinical Neurosciences, vol. 17, no. 4, pp. 478-485, 2005.

[56] K. Grajny, H. Pyata, K. Spiegel et al., "Depression symptoms in chronic left hemisphere stroke are related to dorsolateral prefrontal cortex damage," The Journal of Neuropsychiatry and Clinical Neurosciences, vol. 28, no. 4, pp. 292-298, 2016.

[57] N. Marrus, A. Belden, T. Nishino et al., "Ventromedial prefrontal cortex thinning in preschool-onset depression," Journal of Affective Disorders, vol. 180, pp. 79-86, 2015.

[58] Y. Yang, D. Yang, G. Tang et al., "Proteomics reveals energy and glutathione metabolic dysregulation in the prefrontal cortex of a rat model of depression," Neuroscience, vol. 247, pp. 191-200, 2013.

[59] Y. B. Wei, P. A. Melas, J. C. Villaescusa et al., "MicroRNA 101b is downregulated in the prefrontal cortex of a genetic model of depression and targets the glutamate transporter SLC1A1 (EAAT3) in vitro," International Journal of Neuropsychopharmacology, vol. 19, no. 12, 2016.

[60] J. Zhao, R. W. H. Verwer, D. J. van Wamelen et al., "Prefrontal changes in the glutamate-glutamine cycle and neuronal/glial glutamate transporters in depression with and without suicide," Journal of Psychiatric Research, vol. 82, pp. 8-15, 2016.

[61] G. Treccani, K. Gaarn du Jardin, G. Wegener, and H. K. Müller, "Differential expression of postsynaptic NMDA and AMPA receptor subunits in the hippocampus and prefrontal cortex of the flinders sensitive line rat model of depression," Synapse, vol. 70, no. 11, pp. 471-474, 2016.

[62] W. Wang, H. Guo, S. Zhang et al., “Targeted metabolomic pathway analysis and validation revealed glutamatergic disorder in the prefrontal cortex among the chronic social defeat stress mice model of depression," Journal of Proteome Research, vol. 15, no. 10, pp. 3784-3792, 2016.

[63] X.-C. Liu, S. Erhardt, M. Goiny, G. Engberg, and A. A. Mathé, "Decreased levels of kynurenic acid in prefrontal cortex in a genetic animal model of depression," Acta Neuropsychiatrica, pp. 1-5, 2016.

[64] D. Arnone, A. N. Mumuni, S. Jauhar, B. Condon, and J. Cavanagh, "Indirect evidence of selective glial involvement in 
glutamate-based mechanisms of mood regulation in depression: meta-analysis of absolute prefrontal neuro-metabolic concentrations," European Neuropsychopharmacology, vol. 25, no. 8, pp. 1109-1117, 2015.

[65] G. Chen, D. Yang, Y. Yang et al., "Amino acid metabolic dysfunction revealed in the prefrontal cortex of a rat model of depression," Behavioural Brain Research, vol. 278, pp. 286-292, 2015.

[66] P. Veeraiah, J. M. Noronha, S. Maitra et al., "Dysfunctional glutamatergic and $\gamma$-aminobutyric acidergic activities in prefrontal cortex of mice in social defeat model of depression," Biological Psychiatry, vol. 76, no. 3, pp. 231-238, 2014.

[67] A. M. McEwen, D. T. A. Burgess, C. C. Hanstock et al., "Increased glutamate levels in the medial prefrontal cortex in patients with postpartum depression," Neuropsychopharmacology, vol. 37, no. 11, pp. 2428-2435, 2012.

[68] A. G. Walker, C. J. Wenthur, Z. Xiang et al., "Metabotropic glutamate receptor 3 activation is required for long-term depression in medial prefrontal cortex and fear extinction," Proceedings of the National Academy of Sciences of the United States of America, vol. 112, no. 4, pp. 1196-1201, 2015.

[69] O. Kaut, I. Schmitt, A. Hofmann et al., "Aberrant NMDA receptor DNA methylation detected by epigenome-wide analysis of hippocampus and prefrontal cortex in major depression," European Archives of Psychiatry and Clinical Neuroscience, vol. 265, no. 4, pp. 331-341, 2015.

[70] K. Ma, L. Guo, A. Xu, S. Cui, and J.-H. Wang, "Molecular mechanism for stress-induced depression assessed by sequencing miRNA and mRNA in medial prefrontal cortex," PLoS ONE, vol. 11, no. 7, Article ID e0159093, 2016.

[71] Y. Dwivedi, B. Roy, G. Lugli, H. Rizavi, H. Zhang, and N. R. Smalheiser, "Chronic corticosterone-mediated dysregulation of microRNA network in prefrontal cortex of rats: relevance to depression pathophysiology," Translational psychiatry, vol. 5, p. e682, 2015.

[72] M. Kinou, R. Takizawa, K. Marumo et al., "Differential spatiotemporal characteristics of the prefrontal hemodynamic response and their association with functional impairment in schizophrenia and major depression," Schizophrenia Research, vol. 150, no. 2-3, pp. 459-467, 2013.

[73] N. Tsujii, W. Mikawa, E. Tsujimoto et al., "Relationship between prefrontal hemodynamic responses and quality of life differs between melancholia and non-melancholic depression," Psychiatry Research-Neuroimaging, vol. 253, pp. 26-35, 2016.

[74] S. Pu, K. Nakagome, T. Yamada et al., "Prefrontal activation predicts social functioning improvement after initial treatment in late-onset depression," Journal of Psychiatric Research, vol. 62, pp. 62-70, 2015.

[75] H. Akashi, N. Tsujii, W. Mikawa, T. Adachi, E. Kirime, and O. Shirakawa, "Prefrontal cortex activation is associated with a discrepancy between self- and observer-rated depression severities of major depressive disorder: A Multichannel Near-Infrared Spectroscopy Study," Journal of Affective Disorders, vol. 174, pp. 165-172, 2015.

[76] L. Schulze, S. Wheeler, M. P. McAndrews, C. J. E. Solomon, P. Giacobbe, and J. Downar, "Cognitive safety of dorsomedial prefrontal repetitive transcranial magnetic stimulation in major depression," European Neuropsychopharmacology, vol. 26, no. 7, pp. 1213-1226, 2016.

[77] L. B. Marangell, M. Martinez, R. A. Jurdi, and H. Zboyan, "Neurostimulation therapies in depression: a review of new modalities," Acta Psychiatrica Scandinavica, vol. 116, no. 3, pp. 174-181, 2007.

[78] N. Bakker, S. Shahab, P. Giacobbe et al., "RTMS of the dorsomedial prefrontal cortex for major depression: safety, tolerability, effectiveness, and outcome predictors for $10 \mathrm{~Hz}$ versus intermittent theta-burst stimulation," Brain Stimulation, vol. 8, no. 2, pp. 208-215, 2015.

[79] J. Downar, J. Geraci, T. V. Salomons et al., "Anhedonia and reward-circuit connectivity distinguish nonresponders from responders to dorsomedial prefrontal repetitive transcranial magnetic stimulation in major depression," Biological Psychiatry, vol. 76, no. 3, pp. 176-185, 2014.

[80] J. Prasser, M. Schecklmann, T. B. Poeppl et al., "Bilateral prefrontal rTMS and theta burst TMS as an add-on treatment for depression: a randomized placebo controlled trial," World Journal of Biological Psychiatry, vol. 16, no. 1, pp. 57-65, 2015.

[81] M. Cano, N. Cardoner, M. Urretavizcaya et al., "Modulation of limbic and prefrontal connectivity by electroconvulsive therapy in treatment-resistant depression: A Preliminary Study," Brain Stimulation, vol. 9, no. 1, pp. 65-71, 2016.

[82] N. R. Williams, E. B. Short, T. Hopkins et al., "Five-year follow-up of bilateral epidural prefrontal cortical stimulation for treatment-resistant depression," Brain Stimulation, vol. 9, no. 6, pp. 897-904, 2016.

[83] J. Burgdorf, E. Colechio, P. Stanton, and J. Panksepp, "Positive Emotional learning induces resilience to depression: a role for NMDA receptor-mediated synaptic plasticity," Current Neuropharmacology, vol. 15, no. 8, pp. 3-10, 2017.

[84] D. M. Gerhard, E. S. Wohleb, and R. S. Duman, "Emerging treatment mechanisms for depression: focus on glutamate and synaptic plasticity," Drug Discovery Today, vol. 21, no. 3, pp. 454464, 2016.

[85] P. Belujon and A. A. Grace, "Restoring mood balance in depression: ketamine reverses deficit in dopamine-dependent synaptic plasticity," Biological Psychiatry, vol. 76, no. 12, pp. 927936, 2014.

[86] B. Gellén, K. Völgyi, B. A. Györffy et al., "Proteomic investigation of the prefrontal cortex in the rat clomipramine model of depression," Journal of Proteomics, vol. 153, pp. 53-64, 2017.

[87] F. Guo, Q. Zhang, B. Zhang et al., "Burst-firing patterns in the prefrontal cortex underlying the neuronal mechanisms of depression probed by antidepressants," European Journal of Neuroscience, vol. 40, no. 10, pp. 3538-3547, 2014.

[88] S. Aboul-Fotouh, "Behavioral effects of nicotinic antagonist mecamylamine in a rat model of depression: prefrontal cortex level of BDNF protein and monoaminergic neurotransmitters," Psychopharmacology, vol. 232, no. 6, pp. 1095-1105, 2015.

[89] T. Larrieu, L. M. Hilal, C. Fourrier et al., "Nutritional omega3 modulates neuronal morphology in the prefrontal cortex along with depression-related behavior through corticosterone secretion," Translational Psychiatry, vol. 4, no. 9, article e437, 2014.

[90] M. G. Baxter and E. A. Murray, "The amygdala and reward," Nature Reviews Neuroscience, vol. 3, no. 7, pp. 563-573, 2002.

[91] M.-C. Ko, Y.-H. Hung, P.-Y. Ho, Y.-L. Yang, and K.-T. Lu, "Neonatal glucocorticoid treatment increased depression-like behaviour in adult rats," International Journal of Neuropsychopharmacology, vol. 17, no. 12, pp. 1995-2004, 2014.

[92] K. Zou, W. Deng, T. Li et al., "Changes of brain morphometry in first-episode, drug-naïve, non-late-life adult patients with major depression: an optimized voxel-based morphometry study," Biological Psychiatry, vol. 67, no. 2, pp. 186-188, 2010. 
[93] M. Bellani, M. Baiano, and P. Brambilla, "Brain anatomy of major depression II. Focus on amygdala," Epidemiology and Psychiatric Sciences, vol. 20, no. 1, pp. 33-36, 2011.

[94] H. Lakshminarasimhan and S. Chattarji, "Stress leads to contrasting effects on the levels of brain derived neurotrophic factor in the hippocampus and amygdala," PLoS ONE, vol. 7, no. 1, Article ID e30481, 2012.

[95] B. Karolewicz, K. Szebeni, T. Gilmore, D. Maclag, C. A. Stockmeier, and G. A. Ordway, "Elevated levels of NR2A and PSD-95 in the lateral amygdala in depression," International Journal of Neuropsychopharmacology, vol. 12, no. 2, pp. 143-153, 2009.

[96] S.-D. Chen, Y.-L. Wang, S.-F. Liang, and F.-Z. Shaw, "Rapid amygdala kindling causes motor seizure and comorbidity of anxiety- and depression-like behaviors in rats," Frontiers in Behavioral Neuroscience, vol. 10, article 129, 2016.

[97] W. Li, B. D. Ward, C. Xie et al., "Amygdala network dysfunction in late-life depression phenotypes: relationships with symptom dimensions," Journal of Psychiatric Research, vol. 70, pp. 121-129, 2015.

[98] Y. F. Li, J. C. Yan, D. Q. Wang et al., "Magnetic resonance study of the structure and function of the hippocampus and amygdala in patients with depression," Chinese Medical Journal, vol. 127, no. 20, pp. 3610-3615, 2014.

[99] N. Romanczuk-Seiferth, L. Pöhland, S. Mohnke et al., "Larger amygdala volume in first-degree relatives of patients with major depression," NeuroImage: Clinical, vol. 5, pp. 62-68, 2014.

[100] M. Pilhatsch, N. C. Vetter, T. Hübner et al., "Amygdala-function perturbations in healthy mid-adolescents with familial liability for depression," Journal of the American Academy of Child and Adolescent Psychiatry, vol. 53, no. 5, pp. 559-568, 2014.

[101] K. E. Wonch, C. B. de Medeiros, J. A. Barrett et al., "Postpartum depression and brain response to infants: differential amygdala response and connectivity," Social Neuroscience, vol. 11, no. 6, pp. 600-617, 2016.

[102] Y. Yue, Y. Yuan, Z. Hou, W. Jiang, F. Bai, and Z. Zhang, "Abnormal functional connectivity of amygdala in late-onset depression was associated with cognitive deficits," PLoS ONE, vol. 8, no. 9, Article ID e75058, 2013.

[103] K. R. Luking, G. Repovs, A. C. Belden et al., "Functional connectivity of the amygdala in early-childhood-onset depression," Journal of the American Academy of Child and Adolescent Psychiatry, vol. 50, no. 10, pp. 1027.e3-1041.e3, 2011.

[104] C. G. Connolly, T. C. Ho, E. H. Blom et al., "Resting-state functional connectivity of the amygdala and longitudinal changes in depression severity in adolescent depression," Journal of Affective Disorders, vol. 207, pp. 86-94, 2017.

[105] J. R. Swartz, A. A. Prather, C. R. Di Iorio, R. Bogdan, and A. R. Hariri, "A functional interleukin-18 haplotype predicts depression and anxiety through increased threat-related amygdala reactivity in women but not men," Neuropsychopharmacology, vol. 42, pp. 419-426, 2017.

[106] S. Davidson, L. Shanley, P. Cowie et al., "Analysis of the effects of depression associated polymorphisms on the activity of the BICC1 promoter in amygdala neurones," Pharmacogenomics Journal, vol. 16, no. 4, pp. 366-374, 2016.

[107] A. Qiu, T. T. Anh, Y. Li et al., "Prenatal maternal depression alters amygdala functional connectivity in 6-month-old infants," Translational Psychiatry, vol. 5, no. 2, article e508, 2015.

[108] M. Gilliam, E. E. Forbes, P. J. Gianaros, K. I. Erickson, L. M. Brennan, and D. S. Shaw, "Maternal depression in childhood and aggression in young adulthood: evidence for mediation by offspring amygdala-hippocampal volume ratio," Journal of Child Psychology and Psychiatry and Allied Disciplines, vol. 56, no. 10, pp. 1083-1091, 2015.

[109] N. Doerig, T. Krieger, D. Altenstein et al., "Amygdala response to self-critical stimuli and symptom improvement in psychotherapy for depression," British Journal of Psychiatry, vol. 208, no. 2, pp. 175-181, 2016.

[110] J. Liu, J. Fang, Z. Wang et al., “Transcutaneous vagus nerve stimulation modulates amygdala functional connectivity in patients with depression," Journal of Affective Disorders, vol. 205, pp. 319-326, 2016.

[111] V. Zotev, H. Yuan, M. Misaki et al., "Correlation between amygdala BOLD activity and frontal EEG asymmetry during realtime fMRI neurofeedback training in patients with depression," NeuroImage: Clinical, vol. 11, pp. 224-238, 2016.

[112] S. H. Joshi, R. T. Espinoza, T. Pirnia et al., "Structural plasticity of the hippocampus and amygdala induced by electroconvulsive therapy in major depression," Biological Psychiatry, vol. 79, no. 4, pp. 282-292, 2016.

[113] R. Ramasubbu, A. Burgess, I. Gaxiola-Valdez et al., "Amygdala responses to quetiapine XR and citalopram treatment in major depression: the role of 5-HTTLPR-S/Lg polymorphisms," Human Psychopharmacology, vol. 31, no. 2, pp. 144-155, 2016.

[114] M. Altinay, H. Karne, E. Beall, and A. Anand, "Quetiapine extended release open-label treatment associated changes in amygdala activation and connectivity in anxious depression: an fMRI study," Journal of Clinical Psychopharmacology, vol. 36, no. 6, pp. 562-571, 2016.

[115] C.-T. Li, M.-H. Chen, W.-C. Lin et al., "The effects of low-dose ketamine on the prefrontal cortex and amygdala in treatmentresistant depression: a randomized controlled study," Human Brain Mapping, vol. 37, no. 3, pp. 1080-1090, 2016.

[116] J. E. Castro, E. Varea, C. Márquez, M. I. Cordero, G. Poirier, and C. Sandi, "Role of the amygdala in antidepressant effects on hippocampal cell proliferation and survival and on depressionlike behavior in the rat," PLoS ONE, vol. 5, no. 1, Article ID e8618, 2010.

[117] M. Sekio and K. Seki, "Lipopolysaccharide-induced depressivelike behavior is associated with $\alpha_{1}$-adrenoceptor dependent downregulation of the membrane glurl subunit in the mouse medial prefrontal cortex and ventral tegmental area," International Journal of Neuropsychopharmacology, vol. 18, no. 1, 2015.

[118] A. Haim, M. Sherer, and B. Leuner, "Gestational stress induces persistent depressive-like behavior and structural modifications within the postpartum nucleus accumbens," European Journal of Neuroscience, vol. 40, no. 12, pp. 3766-3773, 2014.

[119] J.-F. Ge, C.-C. Qi, and J.-N. Zhou, "Imbalance of leptin pathway and hypothalamus synaptic plasticity markers are associated with stress-induced depression in rats," Behavioural Brain Research, vol. 249, pp. 38-43, 2013.

[120] E. Albiñana, J. Gutierrez-Luengo, N. Hernández-Juarez et al., "Chondroitin sulfate induces depression of synaptic transmission and modulation of neuronal plasticity in rat hippocampal slices," Neural Plasticity, vol. 2015, Article ID 463854, 12 pages, 2015.

[121] Y. He, D. Kulasiri, and S. Samarasinghe, "Modelling bidirectional modulations in synaptic plasticity: a biochemical pathway model to understand the emergence of long term potentiation (LTP) and long term depression (LTD)," Journal of Theoretical Biology, vol. 403, pp. 159-177, 2016. 

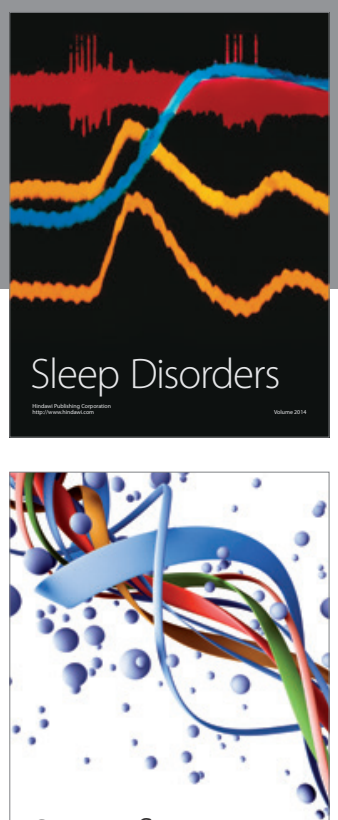

Scientifica
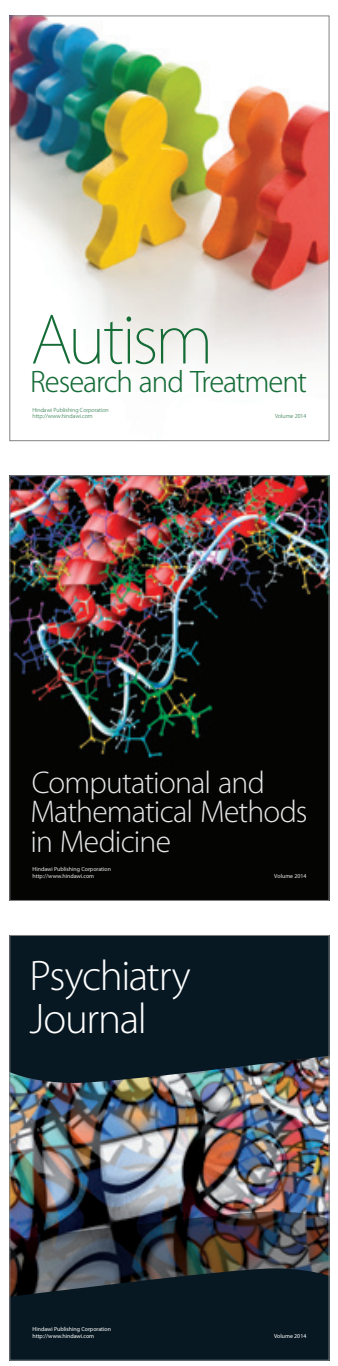
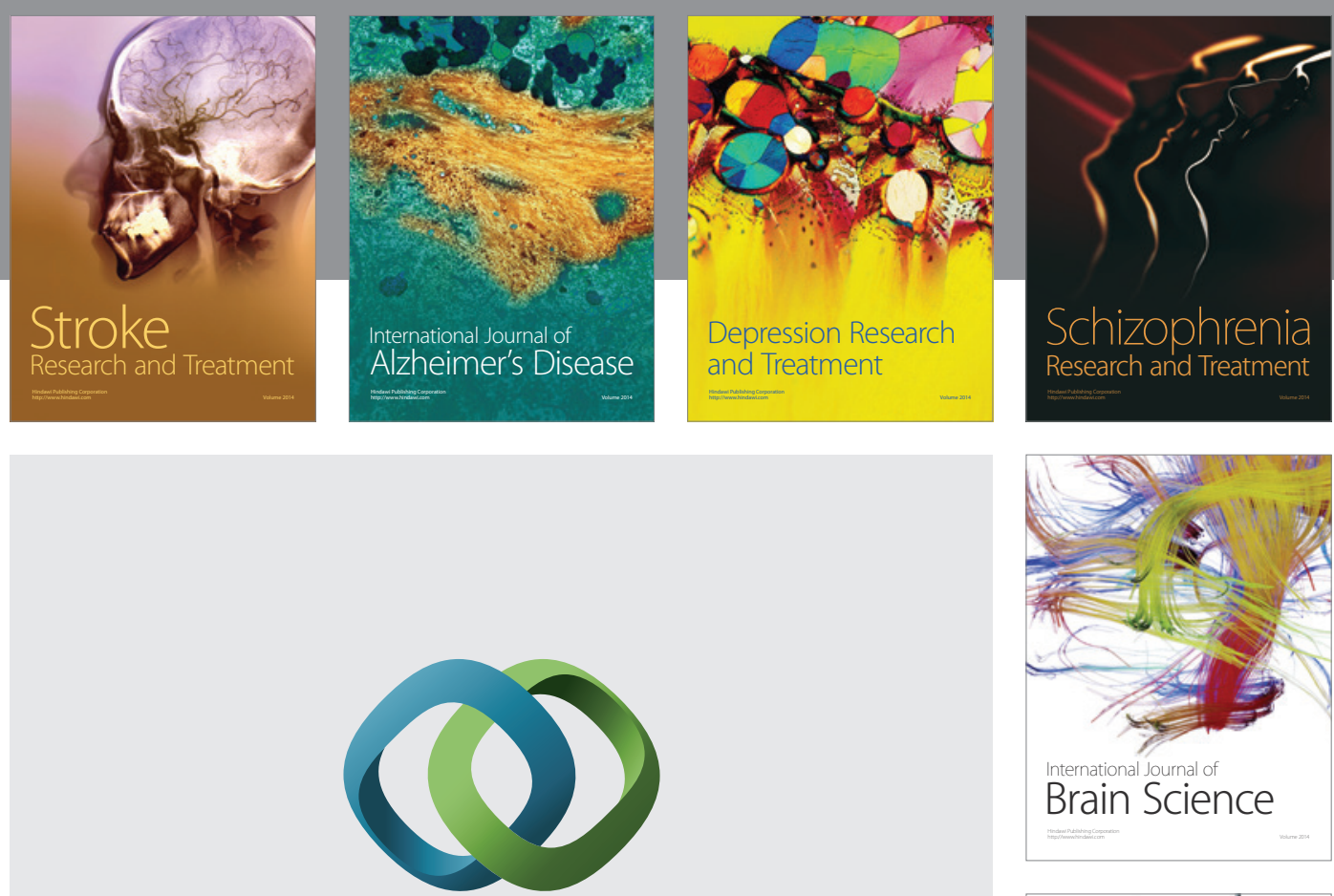

\section{Hindawi}

Submit your manuscripts at

https://www.hindawi.com
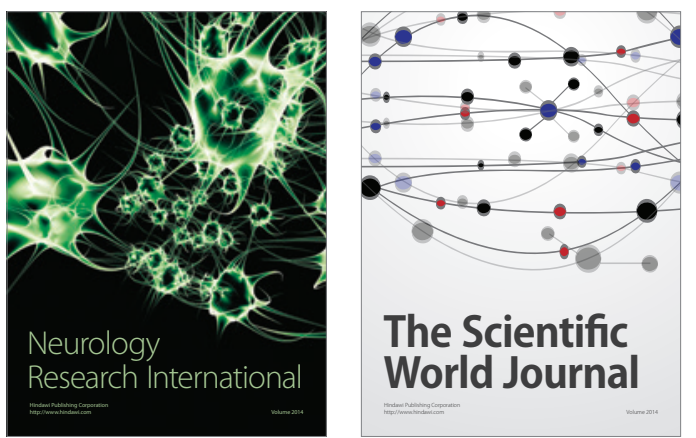

The Scientific World Journal

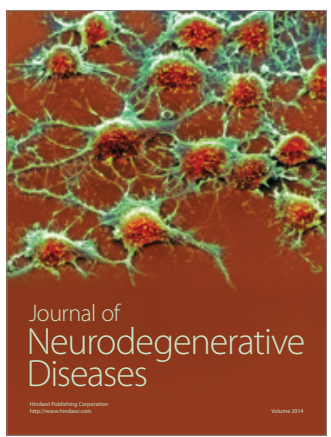

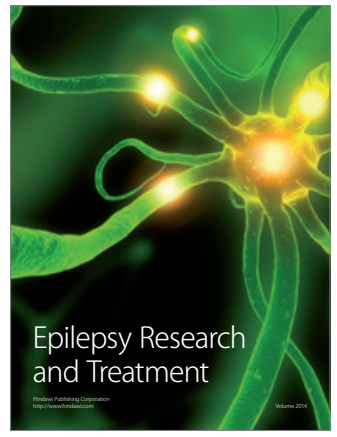

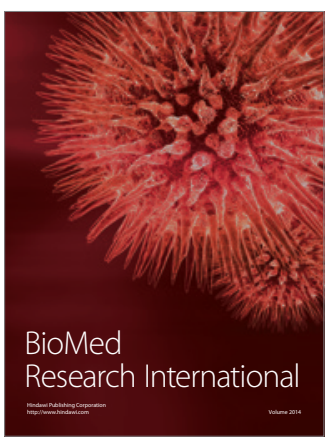

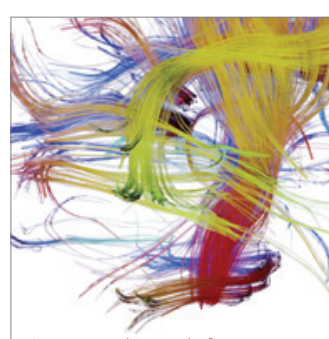

Brain Science

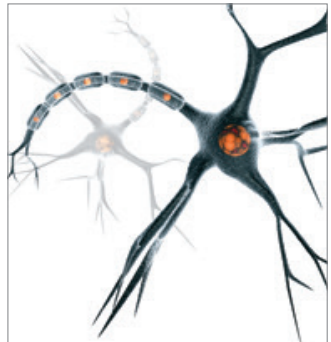

Neural Plasticity
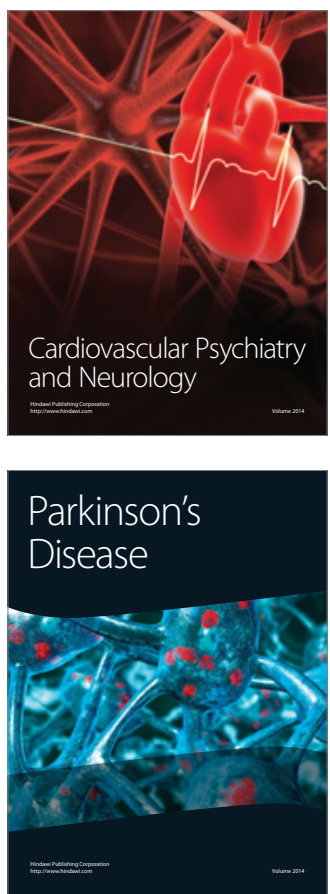